
\title{
CS Research Square \\ Post-Reading Comprehension Questions and Task Types in Vision: A Locally Developed Textbook for Teaching English as a Foreign Language
}

Mavadat Saidi ( $\square$ m.saidi@sru.ac.ir)

Shahid Rajaee Teacher Training University https://orcid.org/0000-0003-3423-5871

Nilufar Karami

Shahid Rajaee Teacher Training University

Morteza Marooy

Shahid Rajaee Teacher Training University

\section{Original article}

Keywords: Affect questions, Content questions, Language questions, Reading, Pos-reading comprehension questions, Vision series

Posted Date: April 5th, 2021

DOl: https://doi.org/10.21203/rs.3.rs-381452/v1

License: () (1) This work is licensed under a Creative Commons Attribution 4.0 International License. Read Full License 


\section{Abstract}

Responding to the call for perusing the post-reading comprehension questions in various EFL textbooks, the current study aimed to investigate the post-reading comprehension questions and task types in the Vision series including three student books and their accompanying workbooks in light of Freeman's (2014) taxonomy. Following a descriptive content analysis procedure, the post-reading comprehension questions in each student books and its accompanying workbook were categorized and counted by the researchers and the Kappa coefficient was 0.97 . The results revealed that Content questions were the most dominant type in all the student books and workbooks except for Vision 3 in which Language questions were the most frequent of all. The results also showed that the highest frequency of post-reading comprehension questions belonged to Explicit (Content) and Form (Language) in student books and Explicit and Implicit (Content), Form (Language), and Personal Response (Affect) in workbooks. The results of Kruskal Wallis test of independent samples indicated a significant difference in terms of Affect type across the student books and workbooks of Vision series. The findings raise the EFL material developers' awareness of the existing post-reading comprehension questions and tasks to enhance the quality of reading sections of EFL textbooks. The results also help the teachers to supplement the books with the missing types and take a comprehensive approach to developing the learners' reading skills.

\section{Introduction}

Textbooks play a key role in language learning and teaching (Garton \& Graves, 2014; Richards, 2014; Tomlinson, 2012). They are considered as "the visible heart of any ELT programme" (Sheldon, 1988, p.237). In this sense, one of the most important sections of the textbooks is reading. Reading either for pleasure or for information (Ur, 1996) is deemed to be an indispensable skill to refresh one's bulk of knowledge (Mckee, 2012) and to facilitate language learning (Freeman, 2014).

In EFL textbooks, for enhancing the effectiveness and attraction of the reading for the language learners and tailoring it to the learning objectives (Ur, 1996), comprehension questions are included (Masuhara, 2013). Being able to answer the comprehension questions as "frequent and time-honored activities" (Aebersold \& Field, 1997, p.117) promotes the language learners' reading comprehension (Anderson \& Biddle, as cited in Grabe, 2009) and thereby, lead them both to take great delight in reading a passage and expand their knowledge (Willis, 2008).

Within the past decades, reading comprehension questions have been examined in light of a cognitively based taxonomy put forth by Bloom (1956). This taxonomy entails six levels: Knowledge, Comprehension, Application, Analysis, Synthesis, and Evaluation. The first three levels encompass less cognitively challenging tasks and questions while the next three levels target higher-order cognitive abilities. Numerous studies have focused on deciphering the levels of tasks and activities in EFL textbooks. For instance, Roohani, Taheri, \& Poorzanganeh (2014) analyzed Four Corners $2 \& 3$ and demonstrated the lower-order level of the activities in these two books. In another study, Interchange Series (2005) was contrarily shown to include activities gearing to higher-order thinking skills (Razmjoo \& Kazempourfard, 2012).

Bloom's taxonomy was used to analyze the reading comprehension questions in elementary and advanced levels of two textbooks, American Headway and Inside Reading (Adli \& Mahmoudi, 2017). The findings were indicative of the dominance of the lower-order thinking skills. Comparing two levels of these books in light of the cognitive 
levels in Bloom's taxonomy, they found significant differences for Knowledge, Comprehension, Application, Evaluation levels while no marked dissimilarities were spotted among the question types in terms of Analysis and Synthesis levels.

Notwithstanding the above studies in which Bloom's taxonomy has been taken as the point of departure, few studies have been allocated to inspecting reading comprehension questions and tasks adopting this framework (Adli \& Mahmoudi, 2017). On the one hand, this model was not especially devised for divulging the cognitive level of $L 2$ reading tasks (Freeman, 2014). On the other hand, several taxonomies have been proposed for scrutinizing reading materials, but they have been given scant attention. For instance, Nuttall (1996) put forth six categories of reading comprehension questions including Literal comprehension, Reorganization and reinterpretation, Inferencing, Evaluation, Personal response, and Writer's wording. Likewise, Day and Park (2005) suggested six question types, namely Literal, Reorganization, Inference, Prediction, Evaluation, and Personal response.

Having undertaken a wide-ranging review of the existing frameworks for categorizing reading comprehension questions, Freeman (2014) proclaimed that "no single taxonomy proved to be wholly suitable and superior to its counterparts" (p.77). Hence, she drew on a combination of the previous taxonomies and new categories and purveyed a fully comprehensive taxonomy. It encompassed three major types of questions, Content, Language, and Affect types. Content questions encompass Explicit, Implicit, and Inferential categories and target the information injected in the text. Language questions consist of Reorganization, Lexical, and Form, and incorporate "language-related tasks" (p.80). Affect questions entails the readers' response to the text comprising Personal Response and Evaluation categories.

Freeman (2014) embarked on her new taxonomy and inquired into the post-reading comprehension questions and task types in four intermediate EFL textbook series including Headway (4 series), American File (2 series), Cutting Edge (2 series), and Inside Out (2 series). The findings revealed the dominance of Content questions in all series, particularly in Headway. Furthermore, the most frequently presented category was Form in American File, which mostly focused on lexical knowledge. The findings further demonstrated the prevalence of Personal Response compared to Evaluation category, which was particularly noticeable in Inside Out.

Baleghizadeh and Zakervafaei (2020) adopted Freeman's (2014) taxonomy and analyzed the post-reading comprehension questions and task types in the Four Corners series. They found that Content questions were the most prevalent categories in the first three levels while language types were dominant in level four. They also found that the most frequent categories in levels one, two, three, and four were Explicit, Personal, Implicit, and Lexical, respectively. Besides, the findings revealed a significant difference among four levels with regard to Explicit, Implicit, Lexical, and Reorganization types. Considering the entire series, Personal Response category had the highest frequency while no reading comprehension questions fell under the Form category.

Except for Freeman (2014) and Baleghizadeh and Zakervafaei (2020), to the best knowledge of the researchers, no study has yet lodged an appeal to this taxonomy for analyzing the reading sections of EFL materials. Freeman (2014) urged that further research should be carried out to peruse the post-reading comprehension questions in various EFL textbooks. On the other hand, the existing studies had taken no notice of comparing the post-reading comprehension questions and tasks of student books and their accompanying workbooks (Baleghizadeh \& Zakervafaei, 2020). Trying to respond to this call for further research and striving to bridge this big gap, the current study aimed to analyze post-reading comprehension questions in the seemingly new series of 
EFL textbooks introduced into the mainstream education, Vision student books and the accompanying workbooks.

This taxonomy unveils different types of questions and tasks that follow a reading passage and can fulfill the function of a reading evaluation checklist (Freeman, 2014). Moreover, it contributes to the teachers' professional expertise in developing materials and illuminates the constituents of a suitable reading passage. Charles (2015) pointed to it as a "useful taxonomy of reading comprehension question types" (p.898). Bearing this in mind, the current study attempted to answer the following research questions:

1) What reading comprehension questions have the highest frequency in Vision 1, 2, 3 student books and workbooks?

2) Is there a significant difference among the frequencies of reading comprehension questions across Vision 1,2 , 3 student books and workbooks?

3) Which reading comprehension questions have the highest and lowest frequency means within Vision series?

\section{Method}

\section{Corpus}

Vision books, in English for Schools series, (Alavimoghaddam, Kheirabadi, Rahimi, and Davari, 2016) consist of three student books $(1,2,3)$, and their accompanying workbooks. Vision 1 and its workbook are comprised of four lessons. Visions 2 and 3 and their corresponding workbooks each contains three lessons. Each lesson consists of eight sections, namely Get Ready, Conversation, New Words and Expressions, Reading, Grammar, Listening and Speaking, Writing, and What You Learned. Visions 1 and 2 have a Pronunciation section. Moreover, Visions 2 and 3 include Vocabulary Development section.

\section{Procedures}

For the purpose of the current study, only the Reading sections (10 reading sections in Student Books and 10 reading sections in Workbooks) were scrutinized considering the reading comprehension questions. These sections included a passage followed by a number of questions. It is worth noting that question here, by no means, implies the interrogative forms but it entails "instructions for any text-related tasks" (Freeman, 2014, p.74).

Freeman's (2014) framework was utilized to count and categorize post-reading comprehension questions. The researchers all categorized the questions separately and average kappa coefficient was 0.97 . The questions which were differently categorized by the researchers were negotiated and a consensus was reached.

To answer the first and third research questions, the frequency and percentage values were compared to explore the least and the most significant question type across Vision student books and workbooks. Furthermore, to answer the second research question, to determine the possible significant difference among the frequencies of reading comprehension questions across Vision 1, 2, 3 student books and workbooks, a Kruskal-Wallis test of independent samples was conducted. To conduct statistical analysis, SPSS was used. 


\section{Results}

Figure 1 displays the frequency of three categories of post-reading comprehension questions in each book of Vision series and its accompanying workbook. It illustrates that Content question type was the most frequent one in Vision 1 (100\%), Vision 2 (76\%), Workbook 1 (85\%), Workbook 2 (76\%), and Workbook 3 (40\%). However, in Vision 3, Language question type (50\%) was the most dominant of all.

Moreover, in Vision 1 and Vision 2, the commonest type of post-reading comprehension questions were Explicit (44\%) while in Vision 3, Form (50\%) question type was the most prevalent of all. Considering the workbooks, the most frequent question types were Implicit (40\%) and Explicit (53\%) in Workbook 1 and Workbook 2. In Workbook 3 , Form (25\%) and Personal Response (25\%) question types were the most frequently used ones.

In general, Content question type was the most prevalent in student books (73\%) and workbooks (67\%). As Table 1 shows, taking into account all the post-reading comprehension questions in the student books, Explicit type was the most prevalent whereas Reorganization and Lexical types were absent. Likewise, the most frequent post-reading comprehension type was Explicit while there was no Reorganization type in the workbooks.

Table 1

Mean values of post-reading comprehension questions in the student books and workbooks

\begin{tabular}{|lllllllll|}
\hline & Explicit & Implicit & Inferential & Reorganization & Lexical & Form & $\begin{array}{l}\text { Personal } \\
\text { Response }\end{array}$ & Evaluation \\
\hline Mean & 2.85 & 2.45 & 0.45 & 0 & 0.10 & 1.40 & 1.05 & 0.35 \\
\hline N & 62 & 50 & 10 & 0 & 1 & 23 & 21 & 6 \\
\hline $\begin{array}{l}\text { Std. } \\
\text { Deviation }\end{array}$ & 2.81 & 1.73 & 0.75 & 0 & 0.30 & 2.32 & 1.57 & 0.67 \\
\hline
\end{tabular}

Table 2 presents the results of the Kruskal Wallis test of $k$ independent samples revealing a significant difference in Personal Response (Sig.= 0.02, $\mathrm{p} \leq 0.05$ ) and Evaluation (Sig. $0.03, \mathrm{p} \leq 0.05$ ) type of post-reading comprehension questions across the student books and workbooks.

Table 2

Significance level of post-reading comprehension questions across student's books and workbooks

\begin{tabular}{|lllllllll|}
\hline & Explicit & Implicit & Inferential & Reorganization & Lexical & Form & $\begin{array}{l}\text { Personal } \\
\text { Response }\end{array}$ & Evaluation \\
\hline $\begin{array}{l}\text { Chi- } \\
\text { Square }\end{array}$ & 9.798 & 9.903 & 8.422 & .000 & 4.046 & 9.194 & 13.155 & 11.731 \\
\hline $\mathrm{df}$ & 5 & 5 & 5 & 5 & 5 & 5 & 5 & 5 \\
$\begin{array}{l}\text { Asymp. } \\
\text { Sig. }\end{array}$ & .081 & .078 & .134 & 1.000 & .543 & .102 & .022 & .039 \\
\hline
\end{tabular}

\section{Discussion}

The current study investigated the most prevalent post-reading comprehension questions in Vision series. The findings revealed that content questions were the most dominant type in all the student books and workbooks 
except for Vision 3 in which Language questions were the most dominant one. In this regard, the results corroborated those of previous studies (Baleghizadeh \& Zakervafaei, 2020; Freeman, 2014).

The study further testified to the high frequency of Explicit and Implicit subtypes of post-reading comprehension questions in Vision student books 1 and 2 and their corresponding workbooks while Form and Personal Response subtypes were the most frequent ones in Vision 3 student book and workbook. In this regard, the results were in line with the previous study by Baleghizadeh and Zakervafaei (2020) who found the high frequency of Language questions in the higher-level books. The study also confirmed their findings in that Reorganization questions were absent. The same results were obtained in the current study.

The highest frequency belonged to Content questions while Language questions were the least dominant of all. It shows the important of Content questions in checking the students' understanding of the major and minor ideas presented in the passages. A decrease in the number of Explicit questions in Vision 3 and its workbook might imply the authors' tendency to foster higher-order thinking skills in higher grades (Freeman, 2014). However, this seems to be refuted by the same trend observed in Implicit and Inferential Comprehension questions across the levels.

On the other hand, an observed increase in the number of Affect questions (both Personal Response and Evaluation) in Vision 3 and its workbook might highlight the significance of involving learners' attitudes and emotions in the reading process (Masuhara, 2013) and relating the language learning activities to the learners' personal lives (Tomlinson \& Masuhara, 2013).

The presence of more Implicit questions compared to other subcategories of Language and Affect categories revealed the focus on enhancing the students' ability to answer the indirectly related questions which seem to be more cognitively demanding. However, Inferential Comprehension questions received scant attention in student books and workbooks. Likewise, Lexical and Reorganization questions were absent in the entire series. These question types would enable the students to tackle the unknown words in the given passages and move toward autonomous learning ( $\mathrm{Na} \&$ Nation, 1985). It seems to be a major objective overlooked by the authors of the book since the target students would take part in University Entrance Examination and they are in desperate need of developing this set of skills to succeed.

The findings ratified those of previous studies (Adli \& Mahmoudi, 2017; Roohani et al., 2014) which revealed the dominance of lower-order thinking skills in EFL textbooks. Nevertheless, the workbooks included more Content and Affect questions, a combination of lower-order and higher-order skills. This might be justified by the role of the workbooks as a supplementary source which aims to extend and expand the skills acquired in the student books (Willis, 2008).

The results further indicated a significant difference in post-reading comprehension questions across the Vision series, student books and workbooks, with regard to Personal Response and Evaluation subcategories of Affect questions. It may imply that the books treated the rest of the questions the same and failed to follow a rationally ascending or descending cognitive trend across the grades.

The results showed that Explicit questions and Reorganization questions were the most and the least frequent question types in the whole series, respectively. The lower frequency of Language questions in the whole series confirmed the results of Baleghizadeh and Zakervafaei (2020) and contrasted those of Tomlinson and Masuhara 
(2013) in that the authors of this series tended to utilize reading texts for teaching reading rather than teaching language. On the other hand, the authors might have taken into account the students' confidence in this stage of language learning and left the higher-order thinking skills to be developed at the university level. However, this might increase the risk of getting the students accustomed to the lower-level thinking activities and tasks following reading passages.

\section{Conclusion}

The current study attempted to analyze the post-reading comprehension questions in Vision series. The findings revealed that Content questions were the most dominant type in all the books except for Vision 3 in which Language questions were the most frequent of all. This might imply the authors' main tendency to develop the students' ability to understand the text (Baleghizadeh \& Zakervafaei, 2020). Ensuring the students' reading comprehension, the authors moved to take advantage of the reading passages for language teaching in higher grades.

Furthermore, the results revealed that the highest frequency of post-reading comprehension questions belonged to Explicit (Content) and Form (Language) in student books and Explicit (Content), Implicit (Content), Form (Language), and Personal Response (Affect) in workbooks. The results also indicated a significant difference in Personal Response and Evaluation question types.

The absence of Reorganization and Lexical subtypes of Language questions might imply that the reading sections aimed to teach the students reading and explicit knowledge of grammar and vocabulary was not addressed (Tomlinson \& Masuhara, 2013). The findings of the current study raise the awareness of the material developers of the type of reading comprehension questions available in the books used in mainstream education. This would help the teachers to supplement the books with the missing types and take an informed approach to developing the students' reading skills through both "teaching reading and teaching language using texts" (Masuhara, 2013, p.170) in order to prepare the students for both lower-order and higher-order cognitive tasks.

To continue this line of research, future studies may focus on analyzing the reading comprehension questions presented in other English series widely used in EFL classes. The supplementary textbooks for Vision series may

be examined in terms of the type of reading comprehension questions to see if they follow the same approach as the main books. Furthermore, the reading comprehension questions posed in nationwide exams, for instance University Entrance Examination, can be studied to see if they require the same skills that the students acquire within the mainstream curricula in order to pursue the possible washback effect.

\section{Abbreviations}

ELT: English Language Teaching; EFL: English as a Foreign Language; L2: Second Language.

\section{Declarations}

\section{Acknowledgements}

The authors acknowledge the anonymous reviewers for their valuable comments. 


\section{Authors' Contributions}

To achieve the purpose of the study, MS developed the design, performed the statistical analysis, and prepared the final draft of the manuscript. NK and MM helped with developing the design, conducting content analysis, and preparing the final draft of the manuscript.

\section{Funding}

There is no funding for this research.

\section{Availability of Data and Materials}

Data is available for submission if required through anonymous email.

\section{Competing Interests}

There is no conflicting interest.

\section{References}

1. Adli, N. \& Mahmoudi, A. (2017). Reading comprehension questions in EFL textbooks and learners' levels. Theory and Practice in Language Studies. 7(7), 590-595. http://dx.doi.org/10.17507/tpls.0707.14

2. Aebersold, J. A \& Field, M. L. (1997). From reader to reading teacher: Issues and strategies for second language classroom. Cambridge University Press.

3. Baleghizadeh, S., \& Zakervafaei, H. R. (2020). Analyzing post-reading comprehension questions and task types in Four Corners. MEXTESOL, 44(1), 1-11.

4. Bloom, B. S. (Ed.) (1956). Taxonomy of educational objectives, Handbook 1: Cognitive domain. Longman.

5. Charles, M. (2015). [Review of the book] English language teaching textbooks: Content, consumption, N. Harwood (Ed.). TESOL Quarterly, 49(4), 897-899. https://www.jstor.org/stable/43893796

6. Freeman, D. (2014). Reading comprehension questions: The distribution of different types in global EFL textbooks. In N. Harwood (Ed.). English language textbooks: Content, consumption, production. (pp. 73-110) Palgrave Macmillan. https://doi.org/10.1057/9781137276285_3

7. Garton, S. \& Graves, K. (2014). Materials in ELT: Current issues in international perspective on materials in ELT. Macmillan. https://doi.org/10.1057/9781137023315_1

8. Grabe, W. (2009). Reading in a second language: Moving from theory to practice. Cambridge University Press.

9. Masuhara, H. (2013). Materials for developing reading skills. In B. Tomlinson (Ed.), Developing materials for language teaching (pp. 265-289). Bloomsbury.

10. Mckee, S. (2012). Reading comprehension, what we know: A review of research 1995 to 2011. Language Testing in Asia, 2(1), 45-58. https://doi.org/10.1186/2229-0443-2-1-45 
11. Na, L. \& Nation, I. S. P. (1985). Factors affecting guessing vocabulary in context. RELC Journal, 16(1). 33-42. https://doi.org/10.1177\%2F003368828501600103

12. Nuttall, C. (1996). Teaching reading skills in a foreign language. Heinemann.

13. Razmjoo, S. A. \& Kazempourfard, E. (2012). On the representation of Bloom's revised taxonomy in Interchange course books. The Journal of Teaching Language Skills, 31(1), 171-204.

https://doi.org/10.22099/JTLS.2012.336 https://doi.org/10.1177/0033688206063470

14. Richards, J. C. (2014). The ELT Textbook. In S. Garton, \& K. Graves (Eds.), International Perspective on Materials in ELT (pp. 19-36). Palgrave Macmillan.

15. Roohani, A., Taheri, F., \& Poorzanganeh, M. (2014). Evaluating Four Corners textbooks in terms of cognitive processes using Bloom's revised taxonomy. Journal of Research in Applied Linguistics, 4(2), 51-67.

http://rals.scu.ac.ir/article_10538.html

16. Sheldon, L. (1988). Evaluating ELT Textbooks and Materials. ELT Journal, 42(4), 237-246. https://doi.org/10.1093/elt/42.4.237

17. Tomlinson, B. (2012). Materials development for language learning and teaching. Language Teaching. 45(2). 143-179. https://doi.org/10.1017/S0261444811000528

18. Tomlinson, B. \& Masuhara, H. (2013). Adult course books. ELT Journal. 67(2), 233-249. https://doi.org/10.1093/elt/cct007

19. Ur, P. (1996). A Course in language teaching: Practice and theory. Cambridge University Press.

20. Willis, J. (2008). Teaching the brain to read: Strategies to improve fluency, vocabulary, and comprehension. Association for Supervision and Curriculum Development.

\section{Figures}




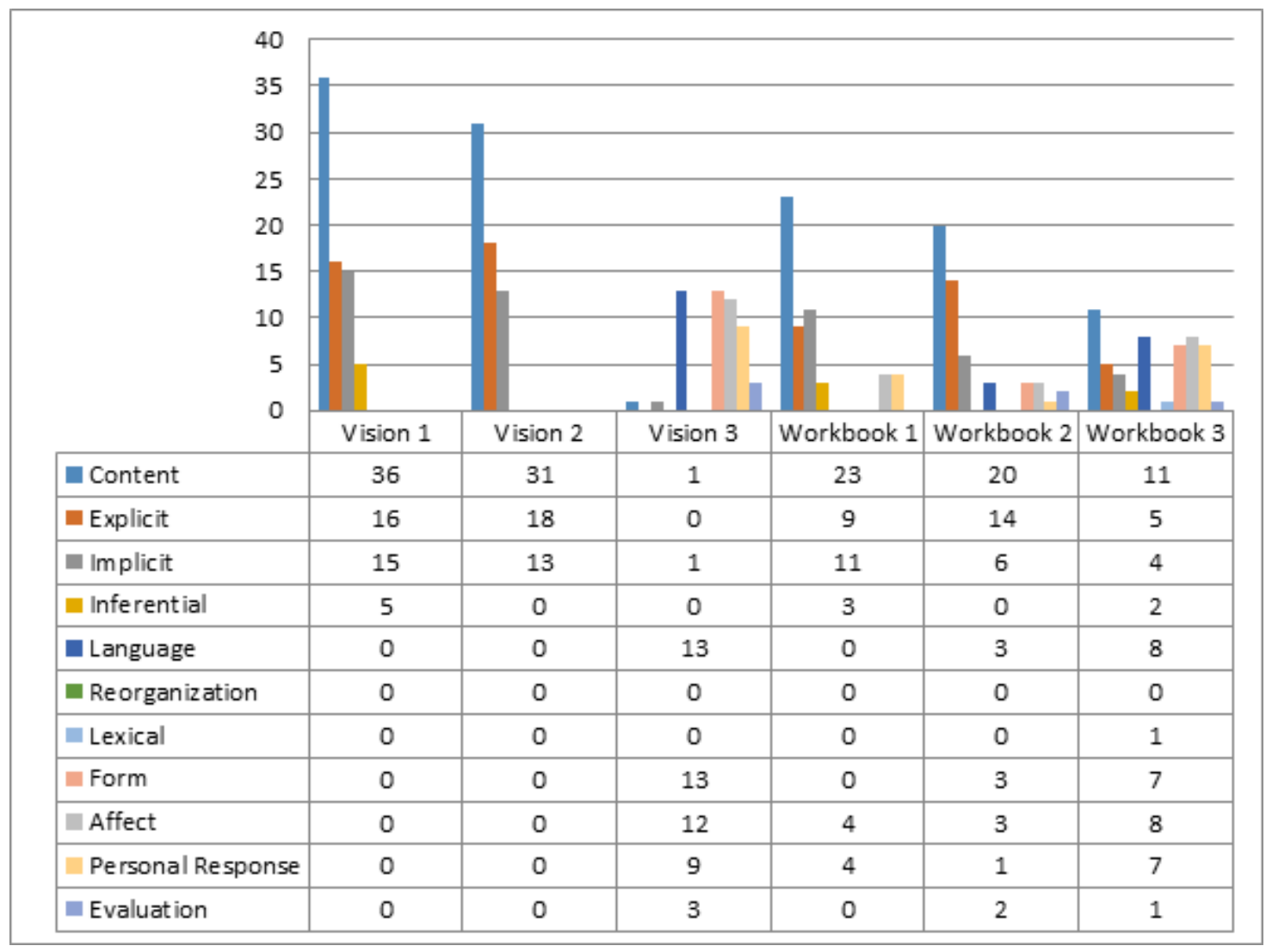

\section{Figure 1}

Frequency of each category of post-reading comprehension questions across the student's books and workbooks 